\title{
NATURE OF THE EFFECTS OF ALTERNATING CURRENT SHOCK ON THE SINUS VENOSUS OF THE TOAD
}

\author{
Masayosi Goto, Hirosi Hara, Hiroshi Kawata \\ AND Issei ImANAGA \\ Department of Physiology, School of Medicine \\ Kyushu University, Fukuoka, Japan
}

Strong electrical stimuli were shown by Whalen (1958) and Whalen, FISHMAN \& ERICKSON (1958) to cause either an augmentation or depression of contractions in the cat papillary or atrial muscle, depending upon the relative amounts of norepinephrine and acetylcholine liberated by the stimulation. These results were confirmed by FurchgotT, DE GUBAREFF \& GRossman (1959) who indicated further that the release of transmitters does not account for changes in the contraction elicited by threshold stimuli. However, BRADY, Aввотт \& MommaerTs (1960) have demonstrated that, in the cat ventricular muscle, a train of supramaximal stimuli produces two actions, a depression of contraction during stimulation and a large potentiation of subsequent contractions. These authors ascribed the former effect to a direct action upon the cell membrane and the latter to a liberation of norepinephrine. Thus, the inotropic effects of strong and weak shocks are quite complicated, although selective stimulation of intra-cardiac postganglionic nerve fibers is possible as shown by LEWARTOWSKI (1963) and VINCENZI \& WEST (1963).

On the other hand, the chronotropic effect of electrical stimuli have been demonstrated by West (1961), AMORY \& West (1962), and CoRABoeuf, SueKANE \& BRETON (1965) on the mechanical and transmembrane activities of the rabbit heart, and the details of membrane potential change have been studied by LU, LANGE \& BROOKS (1965) on the cat sinoatrial node. They found that strong shocks cause cardiac arrest or bradycardia followed by tachycardia with transient hyperpolarization in the nodal cells. Also the hyperpolarization and rate retarding effect are ascribed to a liberation of acetylcholine from the embedded nerve elements, and the secondary trachycardia to that of norepinephrine (see also AMORY \& WEst, 1962; VinCENZI \& WEST, 1963).

Received for publication June 1, 1966

後藤昌義, 原寛, 河山滥, 今永一成 
However, certain aspects of the inotropic and chronotropic effects, particularly differences in effect of direct and indirect actions, still remain to be solved. In this preliminary experiment on the isolated toad sinus venosus, it will be shown that the direct effects of electrical stimulation on the muscle can be divided into two parts; one on the membrane and the other on the intracellular elements. The indirect actions such as inotropic and chronotropic after-effects, on the other hand, are attributable mainly to the cholinergic and adrenergic transmitter actions. The grade and time-course of the effect, however, altered considerably depending on the condition of the preparation and of the stimulation, and three phases of after-potentiation were elucidated by massive electrical stimulation. The appearance of three phases was noted to relate to a liberation of catecholamines from different storage compartments.

\section{METHODS}

The sinus venosus isolated from the toad in the winterm onths (January to April) was used. The strip of about $2 \mathrm{~mm} \times 7 \mathrm{~mm}$, which was immersed in a lucite chamber containing Ringer's solution, was fixed at one end to the wall and the other end to the sensitive arm of a resistance wire strain gauge. A pair of grid electrodes $10 \mathrm{~mm} \times 40 \mathrm{~mm}$ wide were placed with $10 \mathrm{~mm}$ interpolar distance parallel to the long axis of the strip in the middle. Thus, massive stimulation with alternating current of 60 cycles was applied to the strip at definite intervals of about 5 minutes, and the effects on the spontaneous rhythm and isometric contractile tension were observed. The voltages used for stimulation were strictly confined within a range of apparent full reversibility.

The Ringer's solution composition in $\mathrm{mM}$ was $\mathrm{NaCl}, 110.35 ; \mathrm{KCl}, 2.50 ; \mathrm{CaCl}_{3}, 2.15$; $\mathrm{NaHCO}_{3}, 2.38$; glucose, 5.50. The solution was kept flowing continuously in order to minimize the temperature rise due to the stimulating current. The small temperature change which nevertheless resulted was determined by means of an electrothermometer immersed in the solution between the electrodes.

\section{RESULTS}

1. General effects of alternating current on the sinus node. FIG. 1A illustrates the effects of electrical stimulation of $10 \mathrm{~V} / \mathrm{cm}$ and $5 \mathrm{sec}$ duration on the mechanical activity. As shown in the figure, the effects could be divided conveniently into an immediate effect (IE) during current flow and an aftereffect (AE) after cessation of the current. The after-effect appeared further to be subdivided into an after-inhibition (AI) and an after-augmentation (AA).

FIG. $1 \mathrm{~B}$ and $1 \mathrm{C}$ show the effects of alteration in duration and in intensity of the massive stimulation respectively. As seen in these figures, any increase in duration or strength of the alternating current generally evoked greater depression followed by potentiation. Stimuli only slightly above threshold, however, resulted frequently in potentiation not preceded by depression.

FIG. 2 demonstrates the appearance of three phases of the after-potentiation in tension when the duration of stimulation was altered. The left figure 

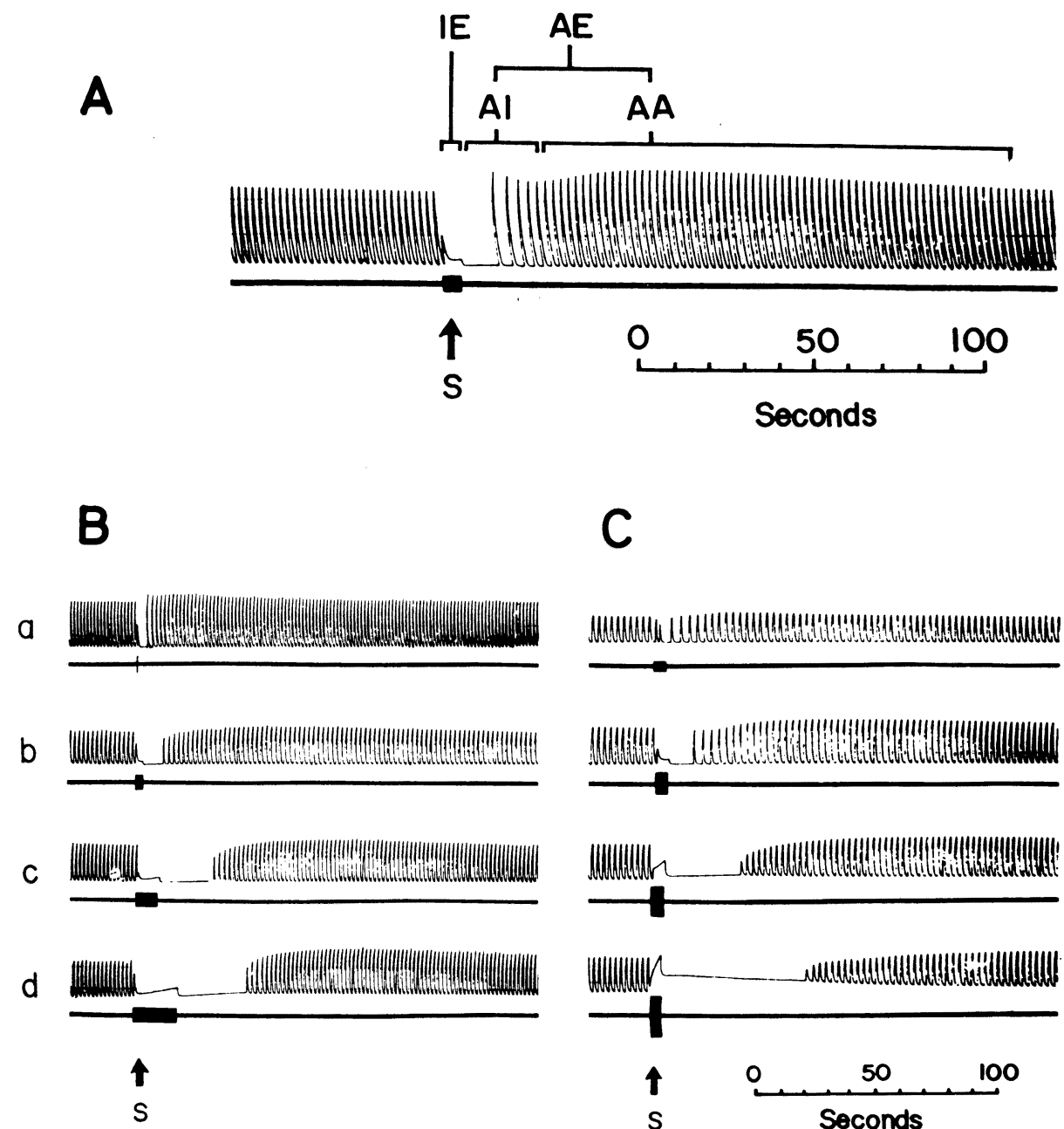

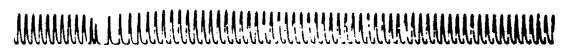

Fig. 1. Action of the alternating current on spontaneous contraction of the toad sinus venosus. A) A record showing general effects. S: Electrical stimulation at 10 $\mathrm{V} / \mathrm{cm}$ and $5 \mathrm{sec}$ duration. IE : Immediate effect during stimulation. AE : After-effect, which consists of after-inhibition (AI) and after-augmentation (AA). The tension change does not appear in parallel with that of rhythm. B) Effects of alteration in duration of the stimuli. (a) $1 \mathrm{sec}$, (b) $4 \mathrm{sec}$, (c) $10 \mathrm{sec}$, (d) $20 \mathrm{sec}$ stimulation at 10 $\mathrm{V} / \mathrm{cm}$. C) Effects of alteration in voltage. (a) $4.0 \mathrm{~V}$, (b) $12.5 \mathrm{~V}$, (c) $27.5 \mathrm{~V}$, (d) 40.0 $\mathrm{V} / \mathrm{cm}$ stimulation of $5 \mathrm{sec}$ duration.

(A) shows a series of time-courses of the peak tension level observed in a normal condition, and the right figure (B) illustrates the actual records obtained from a deteriorated preparation. Note the changes in mode of appearance of the first, second and third potentiation phases (I, II and III) depending on the duration of stimulation. Similar changes in three phases of the potentiation 
A

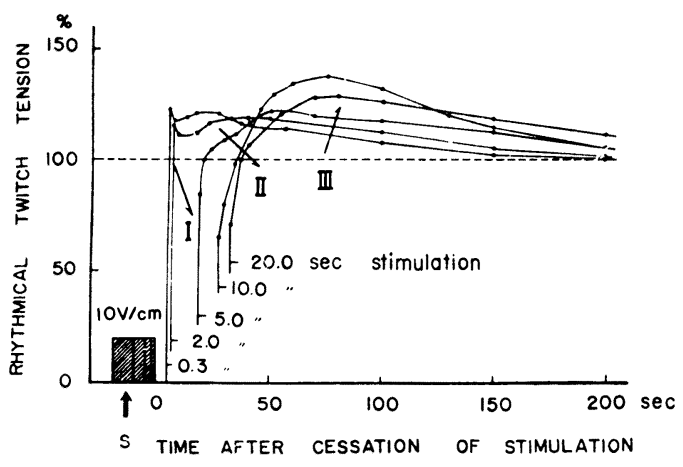

B

a

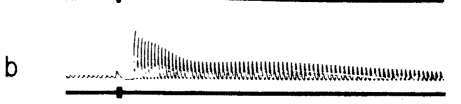

c

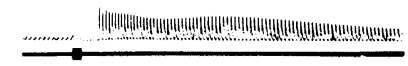

d

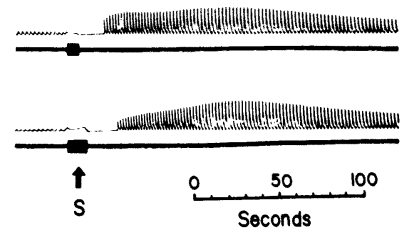

FIG. 2. Appearance of three phases in the after-potentiation. A) Time-courses of the peak tension level of rhythmical contractions after electrical stimulation of different durations. B) Actual records in similar conditions but obtained from a deteriorated preparation.

were also observed when the strength of stimulation was altered.

On the other hand, a deceleration followed by an acceleration of the pacemaker rhythm was usually produced by the mass stimulation. Although their time-courses were not analysed in detail, the chronotropic and inotropic effects of the current did not necessarily appear in parallel with each other (see Fig. 6).

2. Immediate effects of the current flow on the sinus node. The immediate effects of electrical stimulation when the voltage was less than about $1.7 \mathrm{~V} / \mathrm{cm}$ were an acceleration of the riythm and a depression of the contractile tension (FIG. 3). The higher voltages from about $1.7 \mathrm{~V}$ to $5.0 \mathrm{~V} / \mathrm{cm}$ caused an irregularity in the rhythm and contractile tension, probably because of the appearance of fibrillation. Further increase in voltage caused complete depression of the rhythmical contraction and instead the appearance of sustained contraction (FIG. 1C).

FIG. 3A shows the effect of low voltage stimulation on the activity under normal conditions. FIG. $3 \mathrm{~B}$ and $\mathrm{C}$ illustrate the action of acetylcholine $\left(10^{-6}\right.$ $\mathrm{g} / \mathrm{ml})$ and atropine $\left(10^{-7} \mathrm{~g} / \mathrm{ml}\right)$ respectively. The voltage range at which fibrillatory contractions appeared was slightly lowered by acetylcholine, while it was raised by atropine. There was also a general enhancement of the afterinhibition by acetylcholine. On the other hand, atropine caused a dramatic abolition of the after-inhibition.

FIG. 4 summarizes the relations between the voltage of stimulation and the immediate effects, in (A) on the tension and in (B) on the rhythm. As seen in these figures, there was a definite voltage range in which fibrillatory contractions appeared. This range was shifted to lower voltage levels by 
A

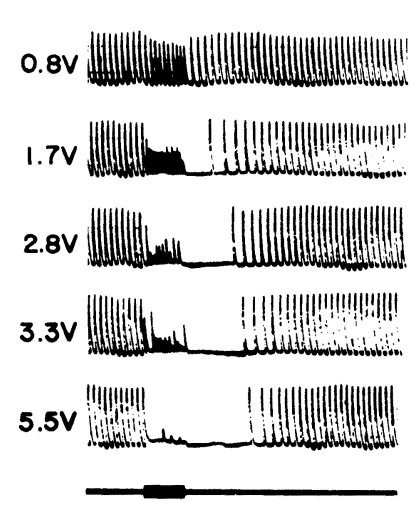

B
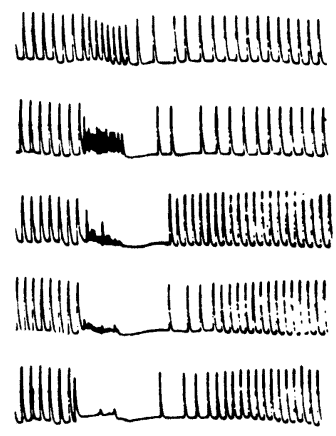

50 100 Seconds
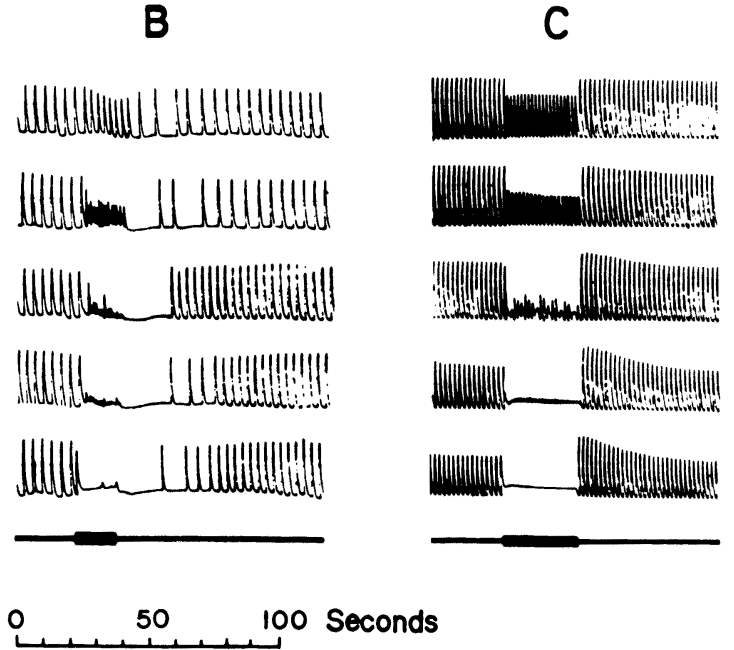

FIG. 3. Action of acetylcholine and atropine on the effect of long lasting alternating current of weak intensity. A) Control records. B) After addition of acetylcholine $\left(10^{-6} \mathrm{~g} / \mathrm{ml}\right)$ and $\left.\mathrm{C}\right)$ atropine $\left(10^{-7} \mathrm{~g} / \mathrm{ml}\right)$. Voltage of stimulation is show $\mathrm{n}$ the left side of the records. Duration of stimulation was $20 \mathrm{sec}$ in $\mathrm{A}$ and $\mathrm{B}$, and $30 \mathrm{sec}$ in $\mathrm{C}$.

acetylcholine and to higher voltage levels by atropine as noted above (see also FIG. 4B).

In any case, a further increase in stimulation voltage produced a sustained contraction, which persisted and even grew during current flow (FIG's 1C and $5)$. The peak tension of the sustained contraction increased linearly with further increase in voltage of the stimulation up to $35 \mathrm{~V} / \mathrm{cm}$, when it reached about $150 \%$ of the maximum tension of the normal rhythmic contraction. This sustained contraction is thought to be produced by direct stimulation of the intracellular elements, since it was produced even after the membrane excitability and twitch contraction were completely eliminated by the action of procaine $\left(10^{-3} \mathrm{~g} / \mathrm{ml}\right)$ or by tris-chloride replacement of all external sodium ions. Therefore, the sustained contraction may become a useful indication of the contractility of the cardiac muscle though further studies are necessary.

3. Nature of, the after-effects and action of the autonomic transmitters. A series of control experiments showed that the special after-effects of the current on the sinus venosus were almost independent of the temperature rise due to the current flow, but principally dependent on the autonomic transmitter actions.

As already shown, electrical stimulation usually produced either a complete arrest or marked reduction in rhythm of the pace-maker activity despite the increase in heart rate expected from a rise of temperature. Fig. 6 illustrates 


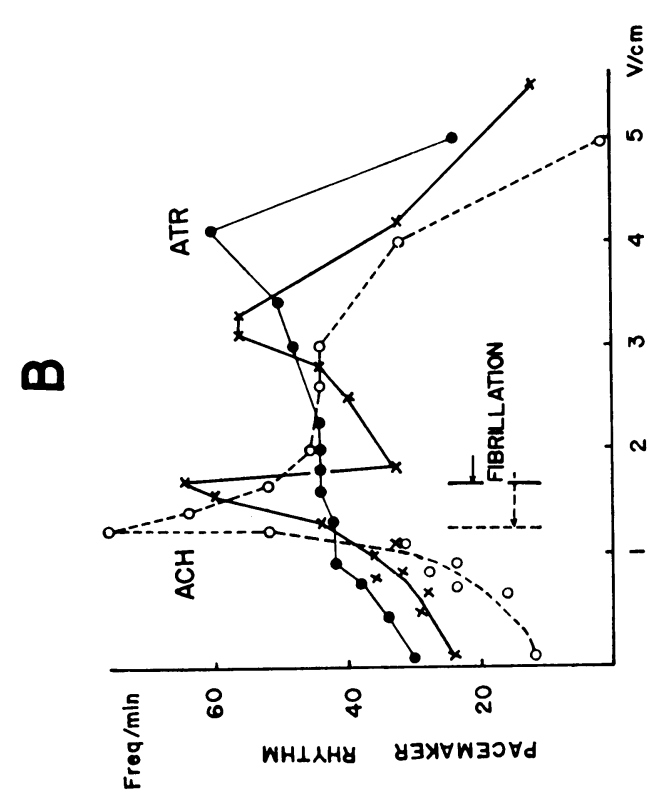

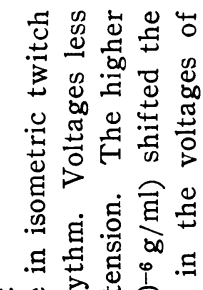

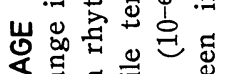
文焉.

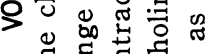

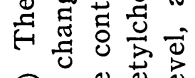
४⿻

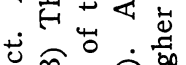

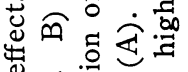
ญ 要 要的焉 ¿

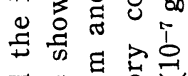
몰 究

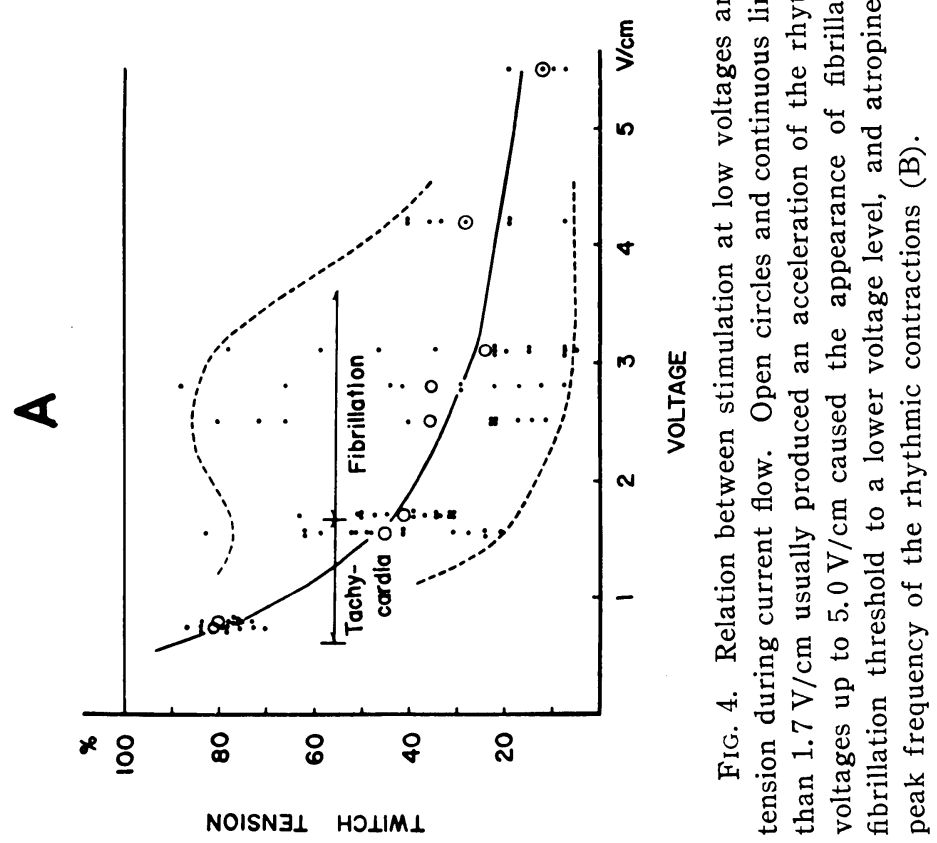


A

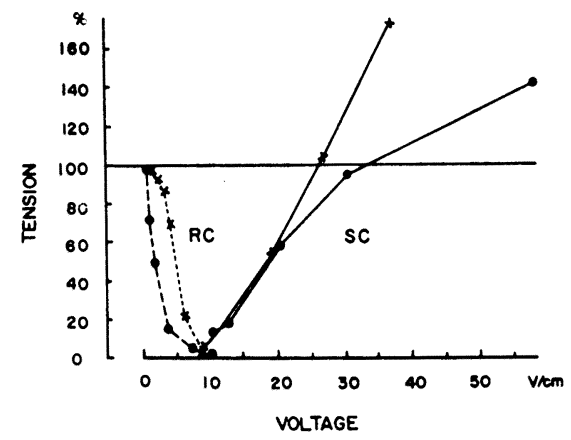

B

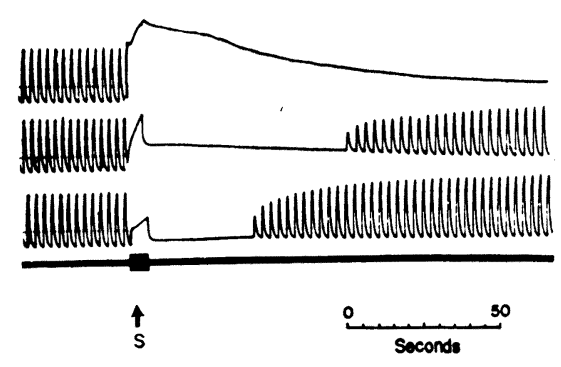

FIG. 5. Dependence of the immediate effect on voltage of the electrical stimulation. A) Voltage-tension relationship. Tension given in percent of normal, 100\% being the control value. The lower voltages affected the rhythmical contraction (RC) while the higher voltages elicited a peculiar sustained contraction (SC). Cross $(x)$ shows the highest value and solid circle (O) denotes the lowest. B) Some of actual records in case of high voltage stimulation. The lower trace is a response to $19 \mathrm{~V}$, the middle to $27 \mathrm{~V}$ and the upper to $36 \mathrm{~V} / \mathrm{cm}, 12 \mathrm{sec}$ stimulation. The stimulation is indicated by an arrow.

a great difference between the actual changes of pace-maker rhythm and the changes predicted from the known temperature dependence of the rhythm. A large difference in contractile tension was also shown between the actual values and the values predicted from the known effect of temperature on contractile tension. Thus, it was concluded that a greater part of the after-effects was not directly related to the temperature change.

On the other hand, acetylcholine $\left(10^{-6} \mathrm{~g} / \mathrm{ml}\right)$ and physostigmine $\left(10^{-6} \mathrm{~g} / \mathrm{ml}\right)$ both enhanced the first after-inhibition markedly, while atropine $\left(5 \times 10^{-8} \mathrm{~g} / \mathrm{ml}\right)$ produced a dramatic disappearance of the inhibition and even caused augmentation (FIG's 7A and B). Similar effects were always observed in spite of considerable changes in duration and intensity of stimulation. Thus, the first inhibitory after-effect of the current appeared mainly due to liberation of acetylcholine by the electrical stimulation.

The second after-effects, acceleration and potentiation were also strengthened by acetylcholine, and the potentiation often appeard in two or three phases. On the other hand, atropine $\left(5 \times 10^{-8} \mathrm{~g} / \mathrm{ml}\right)$ and epinephrine $\left(10^{-6} \mathrm{~g} / \mathrm{ml}\right)$ suppressed the appearance of both the first inhibition and second augmentation and caused an over-all diminution in effects of the electrical stimulation, probably because of the preliminary and overwhelming augmentation (FIG.'s 7B and $\mathrm{C})$. Isoproterenol $\left(10^{-5} \mathrm{~g} / \mathrm{ml}\right)$ produced almost the same results.

Dichloroisoproterenol $\left(10^{-5} \mathrm{~g} / \mathrm{ml}\right)$, blocking the $\beta$-action of epinephrine, caused a marked depression of the pace-maker rhythm and contractile tension. Under these conditions, no acceleration in rhythm was elicited by electrical 


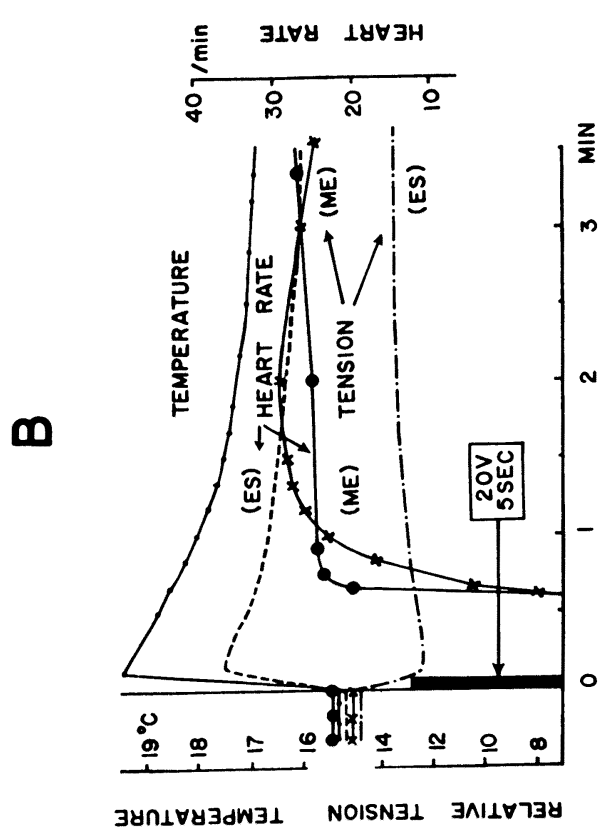

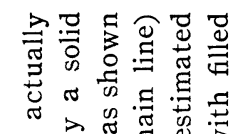

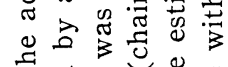

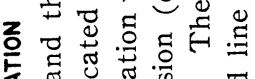

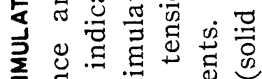

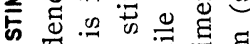

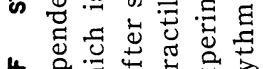

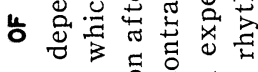

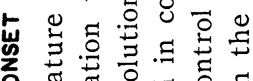

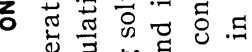

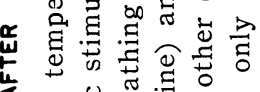
\& Do

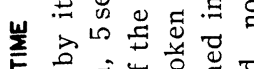

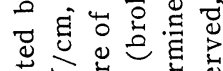
$\Phi>$

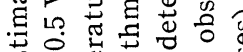

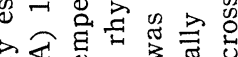

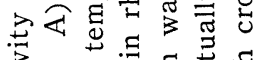

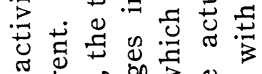

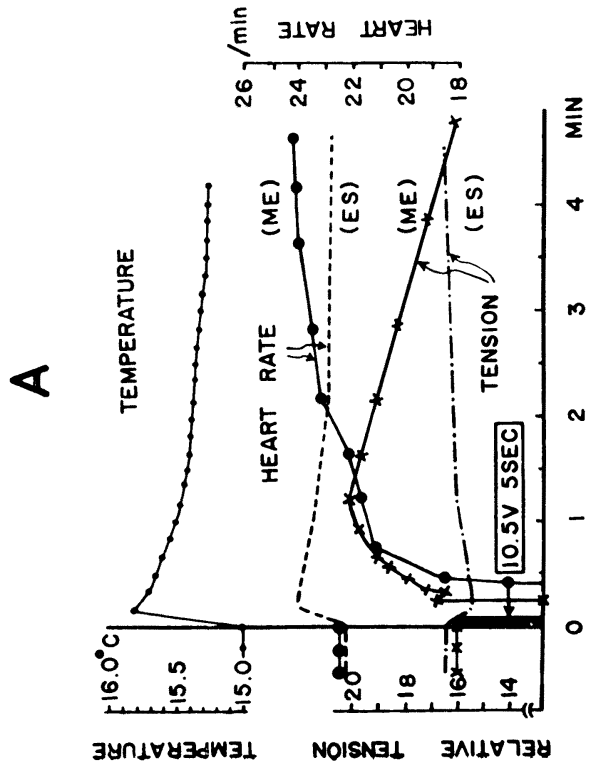

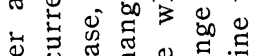
额 政 증

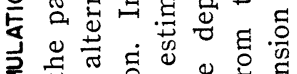

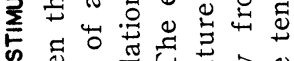
क

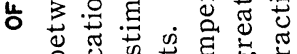

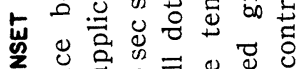
额

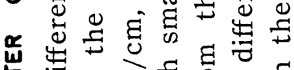

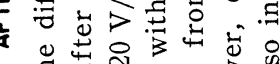

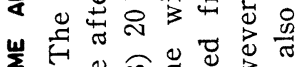
ن

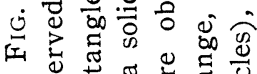

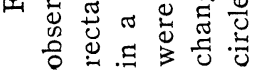


A

a

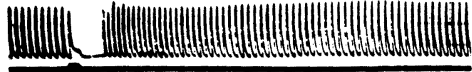

b

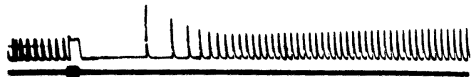

$c$

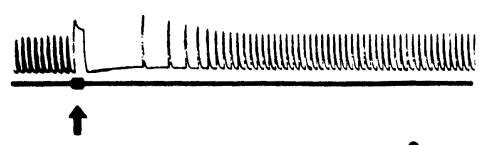

운

C

$a$

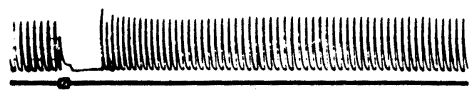

b

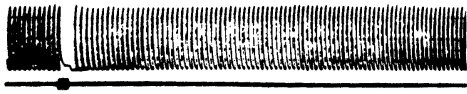

C

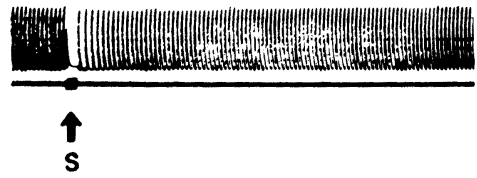

B

$a$

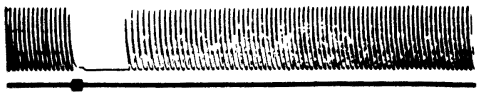

b

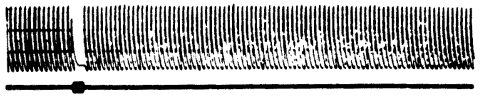

c

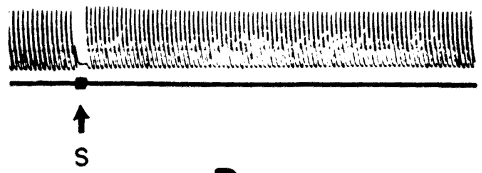

Seconds

$a$

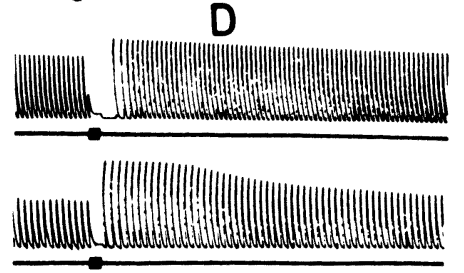

C

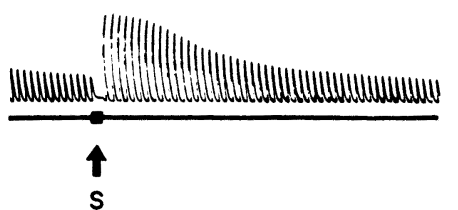

FIG. 7. Effects of acetylcholine, epinephrine and their inhibitors. A) Action of acetylcholine, $10^{-6} \mathrm{~g} / \mathrm{ml}$. B) Atropine, $5 \times 10^{-8} \mathrm{~g} / \mathrm{ml}$. C) Epinephrine, $10^{-6} \mathrm{~g} / \mathrm{ml}$. D) Dichloroisoproterenol, $10^{-5} \mathrm{~g} / \mathrm{ml}$. In each figure (a) shows a control, (b) a record about 5 minutes, and (c) 15 minutes after the application of drug. See further explanation in text.

stimulation, but a transient enhancement of the tension occurred (FIG. 7D). However, the second and third potentiation phases were markedly diminished. Similarly, when reserpine $\left(10^{-5} \mathrm{~g} / \mathrm{ml}\right)$ was applied after brocking the cholinergic inhibition by pretreatment with atropine $\left(10^{-8} \mathrm{~g} / \mathrm{ml}\right)$, the afteracceleration and second and third potentiations were gradually eliminated (FIG. $8 \mathrm{~A})$. On the contrary, when cocaine $\left(2 \times 10^{-5} \mathrm{~g} / \mathrm{ml}\right)$ was given to the preparation pretreated with atropine, first a marked over-all augmentation of the after-potentiations appeared, but next a depression of the second and then first potentiations were gradually developed to cause a complete arrest of the rhythmic activity (FIG. 8B). This arrest could be no more cured by atropine, but a normal rhythmic activity and an ordinal response to electrical shocks were recovered by reintroduction of Ringer's solution. Thus, adrenergic blocking agents which are known to affect different functional sites appeared to inhibit specifically the different phases of after-potentiation. 


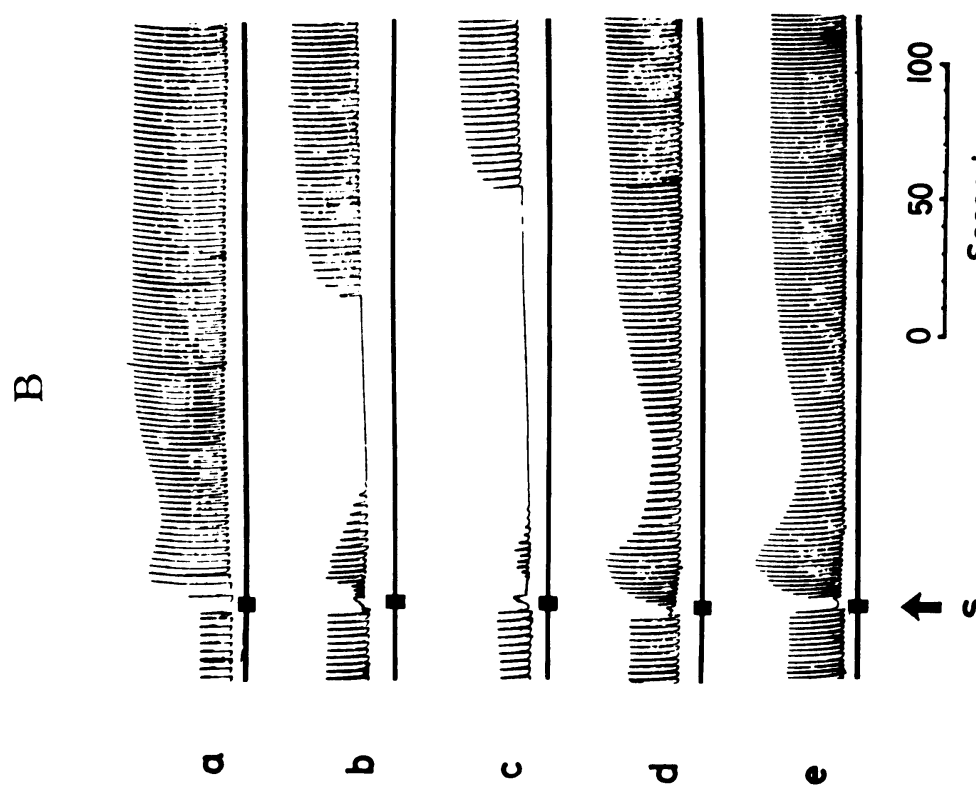

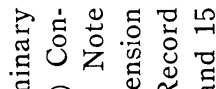
苯 $₫$

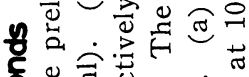

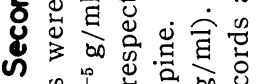
of

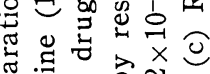

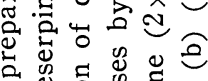

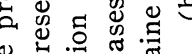

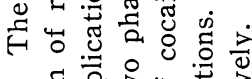

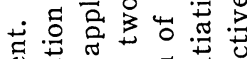

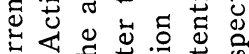
ปे

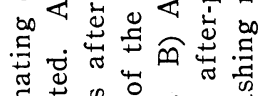

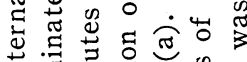

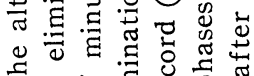

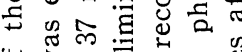
फ 3 चे

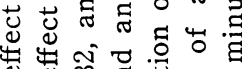
悹出

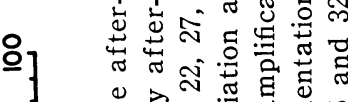

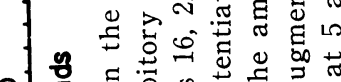

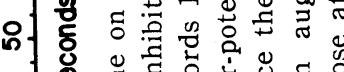

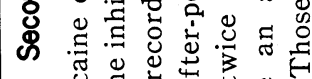

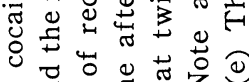

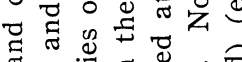

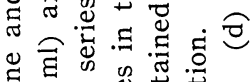
틈

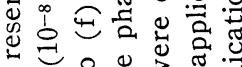
¿\&\$ 0

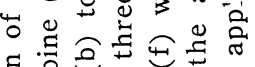

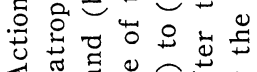

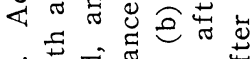

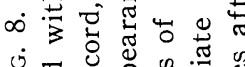

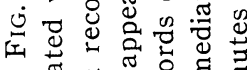

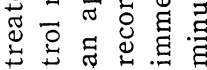




\section{DISCUSSION}

Our experiments on the sinus venosus of the toad showed the immediate effect of low voltage alternating current stimulation to be a depression of contraction and a generation of fibrillatory activity, while in the high vlotage range the current produced a sustained contraction. The tendency to fibrillation was more apparent in strips of ventricle than in strips of the sinus venosus (unpublished observations) which might explain the rapid appearance of ventricular fibrillation in a whole heart subjected to massive electric shocks of low voltages. The sustained contraction was thought to be a product of direct stimulation of the intracellular elements since it appeared even after the membrane excitability was completely eliminated by the action of procaine or by tris-chloride replacement of all external sodium ions. Though detailed study on the membrane potential change has to be done, the sustained contraction must be specially in view point of E-C coupling in the myocardium.

Among the after-effects of alternating current we have observed an inhibition due to acetylcholine liberation followed by a potentiation consisting of three phases, which were attributable to epinephrine action. The observations coincide well with earlier works of WHALEN (1958), WHALEN, FISHMAN \& Erickson (1958), AMory \& West (1962) and Vincenzi \& West (1963), on the warmblooded animals though those authors did not discriminate the three phases. Thus it can be concluded that in the sinus venosus of the toad also depression and augmentation of contractility after strong electrical stimuli are mainly determined by the relative amounts of acetylcholine and epinephrine liberated by the stimulation. BRADy, ABBotT \& Mommaerts (1960) showed that the potentiation can be divided into two phases; the first rise due to an increase in rate of the tension development and the second due to a prolongation of the active state. Although we have observed similar changes in the timecourse of the contraction, the nature of the three potentiation phases in our experiment remains to be clarified.

However, there can be little doubt that at least two storage sites of adrenergic transmitter exist (Trendelenburg, 1961; AxELrod et al. 1962; Kopin et al. 1962; Potter et al. 1963). Weiner et al. (1962) and Axelrod (1963) have postulated three types of sites or pools. FurchgotT et al. (1963) also have studied the actions and interactions of norepinephrine, tyramine and cocaine on strips of thoracic aorta and left atria of the mammals and proposed that there are three types of storage sites; i. e. major but slow compartment $(\mathrm{Sm})$, minor but fast compartment $(\mathrm{Sa})$ and transfer sites $(\mathrm{T})$. If these are also the cases of the amphibian heart, it is highly probable that three potentiation phases in our experiment are some manifestation of the three storage compartments. The elimination of slow major potentiation by reserpine, and 
the temporal augmentation of all phases by cocaine and the following depression of fast potentiations will support this view.

\section{SUMMARY}

1. The effects of alternating current on pace-maker activity have been studied in the isolated toad sinus venosus. The alternating current produced an immediate action followed by an after-inhibition and an after-augmentation.

2. The immediate action of stimulation by voltages less than $1.7 \mathrm{~V} / \mathrm{cm}$ was an acceleration of the rhythm and a depression of the contractile tension, while voltages of $1.7-5.0 \mathrm{~V} / \mathrm{cm}$ caused an irregularity in rhythm and tension. The voltage range in which the irregularity was obtained was lowered by acetylcholine and elevated by atropine.

3. A further increase in stimulation voltage produced, during current flow, a sustained contraction which increased linearly with voltage increase up to $150 \%$ of the peak tension of normal phasic contraction. The sustained contraction appeared even after the elimination of membrane excitability by procaine or by complete lack of external sodium ions, and hence it was thought to be a direct response of the intracellular elements.

4. The first after-effect was an inhibition of both pace-maker rhythm and contractile tension, which appeared prominent at higher voltage of stimulation. The inhibitory effect was strengthened by both acetylcholine and physostigmine, and blocked dramatically by atropine.

5. The second after-effect was an acceleration of the pace-maker rhythm and a potentiation of contractile tension. The potentiation appeared frequently separated into three phases, the fast, middle and slow phases. Dichloroisoproterenol and reserpine blocked the acceleration and eliminated the middle and slow potentiations. Cocain, on the other hand, abolished the fast and middle potentiations after a temporal enhancement of all phases.

6. The after-effects of mass stimulation, therefore, are attributable mainly to cholinergic and adrenergic transmitter actions, and it is postulated that three phases of the after-potentiation relate closely to the liberation of adrenergic transmitters from the different storage compartments.

The authors wish to express their sincere thanks to Prof. C. McC. BRooks for valuable advice while preparing the project and to Dr. R. M. EcCLEs for reading the manuscript and making valuable suggestions.

\section{REFERENCES}

1) Amory, D. W. ANd West, T.C. (1962) Chronotropic response following direct electrical stimulation of the isolated sinoatrial node: a pharmacologic evaluation. J. Pharmacol. Exp. Ther., $137:$ 14-23. 
2) Axelrod, J. (1963) In Clinical Chemistry of Monoamines. Elsevier Publ. Co. New York.

3) Axelrod, J., Gordon, E., Herting, G., Kopin, I. J. And Potter, L. T. (1962) On the mechanisms of tachyphylaxis to tyramine in the isolated rat heart. Brit. J. Pharmacol., 19 : 56-63.

4) Brady, A. J., Abbott, B.C. And Mommaerts, W. F. H. M. (1960) Release of autonomic mediators in cardiac tissue by suprathreshold stimulation. J. Gen. Physiol., 44 : 415-432.

5) Coraboeuf, E., Suekane, K. And Breton, D. (1965) In Electrophysiology of the Heart. Pergamon, Oxford.

6) Furchgott, R. F., De Gubareff T. and Grossman, A. (1959) Release of autonomic mediators in cardiac tissue by suprathreshold stimulation. Science, 129: 328-329.

7) Furchgott, R. F., Kirpekar, S. M., Rieker, M. and Schwab, A. (1963) Actions and interactions of norepinephrine, tyramine and cocaine on aortic strips of rabbit and left atria of guinea pig and cat. J. Pharmacol. Exp. Ther., 142: 39-58.

8) Kopin, I. J. AND GoRdon, E. K. (1962) Metabolism of norepinephrine $\mathrm{H}^{3}$ released by tyramine and reserpine. J. Pharmacol. Exp. Ther., 138: 351-359.

9) LEWARTowski, B. (1963) Selective stimulation of intra-cardiac postganglionic fibers. Nature, 199 : 76-77.

10) LU H-H., LANGE, G. AND BRooks, C. McC. (1965) Factors controlling pacemaker action in cells of the sinoatrial node. Circulation Res., 17:460-471.

11) Potter, L. T. ANd Axelrod, J. (1963) Studies on the storage of norepinephrine and the effect of drugs. J. Pharmacol. Exp. Ther., 140: 199-206.

12) Trendelenburg, U. (1961) Modification of the effect of tyramine by various agents and procedures. J. Pharmacol. Exp. Ther., 134: 8-17.

13) VincenzI, F. F. AND West, T.C. (1963) Release of autonomic mediators in cardiac tissue by direct subthreshold electrical stimulation. J. Pharmacol. Exp. Ther., 141. 185-194.

14) Weiner, N., Draskoczy, P. R. And Burack, W. R. (1962) The ability of tyramine to liberate catecholamines in vivo. J. Pharmacol. Exp. Ther., 137: 47-55.

15) WEst, T.C. (1961) In the specialized tissues of the heart. Elsevier, Amsterdam.

16) Whalen, W. J. (1958) Apparent exception to the "all or none" law in cardiac muscle. Science, $127: 468-469$.

17) Whalen, W. J., Fishman, N. and Erickson, R. (1958) Nature of the potentiating substance in cardiac muscle. Amer. J. Physiol., $194: 573-580$. 